\title{
Women Self-Defense and Security System
}

\author{
Richa Pokhrel $^{*}$, Asmita Jha ${ }^{1}$, Pooja Singh ${ }^{1}$ and Pragya Jha ${ }^{1}$, and Rama Bastola ${ }^{1}$ \\ ${ }^{1}$ Department of Electronics and Computer, Thapathali Campus, Institute of Engineering, \\ Tribhuvan University, Kathmandu, Nepal \\ "Corresponding Email: richapokhrel.bm@gmail.com
}

\begin{abstract}
The main objective of our project is to provide security for human beings especially woman and children with a help of an advanced electronics. As most of the women are subjected to unethical physical harrashment when they are alone in public areas, in case they will be provided with an equipment fitted inside the shoes which is not visible to others, the equipment consists of GPS (Global Positioning System) and GSM module by which the geographical location can be tracked and can be sent. In the case of any emergency conditions, the button is pressed and the microcontroller sends latitude and longitude information to authorized persons through GSM. Then the location information is tracked and the information can be sent to police and family members so that they can be rescued in proper time. At the same time, they will be provided a high voltage generating device embedded within the system can be used to generate electric shock to temprorarily paralyse the criminals in critical situations. The device is portable and hence can be taken anywhere we travel. It is economical and simple to use. So, it can be effective in saving many people (not merely women) from criminal attacks, sexual harassments and can be used as legal evidence of crime.
\end{abstract}

Keywords: Electric Shock, GPS, GSM, Location Tracking, Women Security

\section{INTRODUCTION}

Nowadays, sexual harassment and molestation against women are growing day by day. The case study of fiscal year 2017/2018 has reported 1480 rape, 628 murder and 308 human trafficking cases in Nepal. [1] We are also hearing frequently about 'Nirmala Panta's rape case'. She was a nearly 15-year old girl who was raped and killed by some cruel criminals. However, years passed away but no evidence for this case has been found till date. Criminals are freely wandering around us. But the government, being passive is not showing any interest in these topics. Women are not allowed to walk alone in the streets during nights in the fear such harassment cases. Till date, no self-defense and security device has been made in Nepal.

So, we are proposing a device, based on GPS-GSM technology which can track the location of a person who is in danger. They will also be provided with the high voltage generating device fitted inside the shoes to temporarily paralyse the criminals in critical situations hence can be used for self defense unless anyone comes. The system suggests a smart wearable device for security which contains different modules such as GSM, GPS, shock mechanism circuit and AVR micro-controller. The proposed system helps women in emergency situation by activating the modules on clicking the switch and provide emergency self-defense. 
It has the potential to help women with technologies that are embedded. It is specially designed for women safety and protection. It has a control button that will be used by women to inform nearby police when they are in distress. This system directly gets connected to the satellite through GPS when activated. Then the location is transferred to the authorized and targeted phone number through the GSM, it also contains a shock mechanism to produce non-lethal electric shock in emergency situations to deter the attacker. The prototype can be implemented into digital watch, shoes, bag by reducing the size of the components and can be taken to colleges, hospitals, public places and also in parking system. By integrating a culturallyrelevant educational curriculum (service) with a product (good) that is affordable and accessible, our innovation is helpful in saving women from harassment. In Nepal lots of crime happens against women every day. This device can readily solve this issue. The device can be installed at small scale and we can also try for further progress in the same.

\section{RELATED WORKS}

There is a history where our society is troubled with these unusual activities and is increasing day by day especially related to women harassment and molestation issues. Looking at the past context the security system for self-defense are easily breakable because there was only the use of manpower not the electronics but nowadays the use of modern technologies have fortunately minimized the use of manpower. Thus, the need of this device is an absolute necessity now and in the near future. VithU, is an emergency App that, at the click of the power button of your Smartphone 2 times consecutively begins sending out alert messages every 2 minutes to your contacts that you feed into the app as the designated receivers or guardians. However, continuously using smartphones can easily be tracked by attackers and in the case of kidnapping smart phones are very bad choice for security so this limitation must be overcome. Shot gun is a small gun that charges an attacker with an electric shock. The shock weakens the attacker temporarily, giving you sample chance to escape the scene. When its trigger is pulled, a stun gun pumps about 700,000 volts into the attacker's body. Some stun guns are small enough to be concealed in a pack of cigarettes. They run on Lithium batteries and can be carried either in handbags or held in waist straps. Fight Back app is a very basic app similar to ones listed above with an unique feature i.e. Facebook status update. Apart from providing SMS and Email options to alert the other person during distress, this app also updates your Facebook status. However, it also doesn't have any self defense mechanism. [2]

Our project is inspired by the limitations of all the pre-existing systems and is slightly modified to overcome some of the drawbacks.

\section{HARDWARE REQUIREMENTS}

\subsection{GPS MODULE}

The GPS module is used to get a geographical location of a person by receiving information from satellites and as to provide location information in terms of latitude and longitude. It gives the value of location with an accuracy of degree-minutesecond with one can easily trace out the location of the place and track the position of a women in case of any mishappening. In this GPS technology, the communication takes place between GPS transceiver and GPS satellite.

\subsection{GSM MODULE}

The GSM (Global system for mobile communication) platform is a hugely successful wireless technology underpinning most of the world's mobile network. GSM has become the world's fastest growing communications technology of all time and the leading global mobile standard, spanning 218 countries. GSM is an open, digital cellular technology used for transmitting mobile voice and data services. GSM 
operates in the $900 \mathrm{MHz}$ and $1.8 \mathrm{GHz}$ bands GSM supports data transfer speeds of up to $9.6 \mathrm{kbps}$, allowing the transmission of basic data services such as SMS.

\subsection{ATmega32 MICROCONTROLLER}

AVR is a family of microcontrollers developed since 1996 by Atmel. These are modified Harvard architecture 8-bit RISC single-chip microcontrollers. [3] It combines 32KB ISP flash memory with readwhile-write capabilities, 1KB EEPROM, 2KB SRAM, 23 general purpose I/O lines, 32 general purpose working registers, three flexible timer/counters with compare modes, internal and external interrupts, serial programmable USART, a byte oriented 2-wire serial interface, SPI serial port, 6-channel 10-bit A/D converter (8-channels in TQFP and QFN/MLF packages), programmable watchdog timer with internal oscillator, and five software selectable power saving modes. The device operates between 1.8-5.5 volts. [3] [4]

\subsection{LM 35 TEMPERATURE SENSOR}

LM35 is a precision IC temperature sensor and linear voltage sensor with its output proportional to the temperature (in oC). The sensor circuitry is sealed and therefore it is not subjected to oxidation and other processes. With LM35, temperature can be measured more accurately than with a thermistor. It also possess low self-heating and does not cause more than $0.1 \mathrm{oC}$ temperature rise in still air. The operating temperature range is from $-55^{\circ} \mathrm{C}$ to $150^{\circ} \mathrm{C}$. [5] The output voltage varies by $10 \mathrm{mV}$ in response to every oC rise/fall in ambient temperature, i.e., its scale factor is $0.01 \mathrm{~V} / \mathrm{oC}$.

\subsection{HIGH VOLTAGE GENERATOR}

It is an electric circuit designed using the transformer, inductor, transistors, diodes, capacitor which overall acts as an oscillator and is capable of generating high AC voltage with the help of small DC input voltage. Transformer here used is step-up transformer, IRFZ44 high voltage transistors, 10 pcs 1N4007 diodes and 10 pcs high voltage ceramic capacitors.

\section{SOFTWARE REQUIREMENTS}

\subsection{PROTEUS 8 PROFESSIONAL}

The Proteus Design Suite is a proprietary software tool suite used primarily for electronic design automation. [6] The software is used mainly by electronic design engineers and technicians to create schematics and electronic prints for manufacturing printed circuit boards.

\subsection{ATMEL STUDIO 6}

Atmel Studio 6 is a program designed for developing and debugging Atmel ARM Cortex-M and Atmel AVR microcontroller (MCU) based applications. The Atmel Studio IDP gives us a seamless and easy-touse environment to write, build and debug our applications written in $\mathrm{C} / \mathrm{C}$ or assembly code. [7]

\section{SYSTEM DESCRIPTION AND IMPLEMENTATION}

As shown in the diagram below, prototype of our system comprises of processing and operation of the two separated hardware interfaces: Location tracking and electric shock generation. They are embedded together and fitted inside the shoes with safety. A light weighted 5V-2A Li-ion battery is used to supply 
power to the internal device. There are 3 compatible switches kept hidden inside the shoes. One of the switches is a regular power switch to enable and disable power to the device. Another switch is an emergency switch which when pressed sends the location of the person with URL of google map. The third switch is for self defense for the electric shock generation. The metallic wire for electric shock is kept isolated at the apex of the shoes so that to easily target the criminals without hampering oneself.

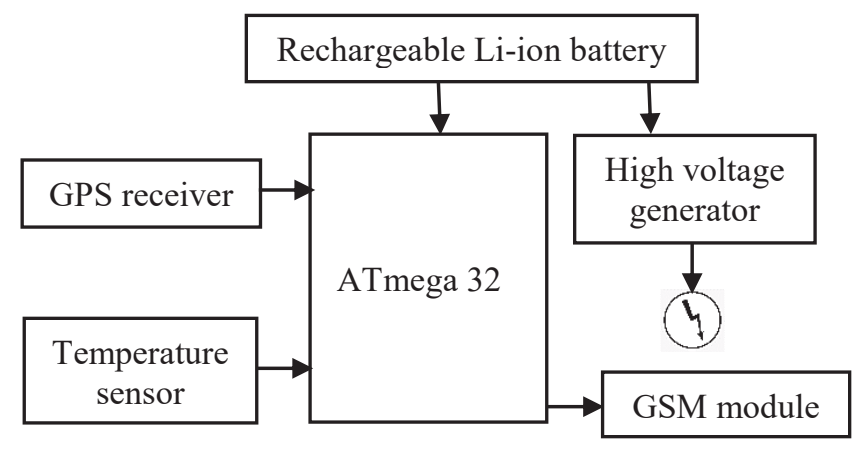

Figure 1: Block Diagram of a system

The first major component used to control all the processes in our system is ATmega32 microcontroller. Neo 6m GPS module and SIM 800L GSM module are connected with microcontroller via serial ports. They are small in size with low power consumption rating.. The GPS receiver and GSM module uses USART; Serial communication protocol to communicate with microcontroller or PC terminal. In this interfacing, AVR based ATmega32 microcontroller will read data serially from GPS receiver using USART communication with 9600 Baud rate. Tx on GPS module is connected to digital pin PD0 (RX) of AVR and Rx on GSM module is connected to digital pin PD1 (TX) of AVR. Two ports PD0 and PD1 of microcontroller have dual purposes are also known as serial ports helps serial data transmission between peripherals and microcontroller. GPS receives many other noisy information from satellite. The microcontroller reads all the data from GPS and extract only the latitudinal and longitudinal value. This value is then attached with Google URL.

Next for obtaining the health status of a person and device, the temperature sensor is kept at the upper sole of a shoes. LM35 sensor provides output based on scale of centigrade. After reading the temperature, sensor gives the analog output to the microcontroller. This analog output from the sensor is sent to the ADC0 of the atmega32 that converts the analog data to the digital by inbuilt ADC in it. The atmega32 has 8 ADC channel i.e. ADC0-ADC7. It means we can connect eight analog sensors. The Port A and ADC pins are multiplexed to each other. The primary function of this pins is as an I/O and secondary is as ADC. To enable the ADC we need to enable it by setting the internal register of the atmega32 by writing the programming code. [8]

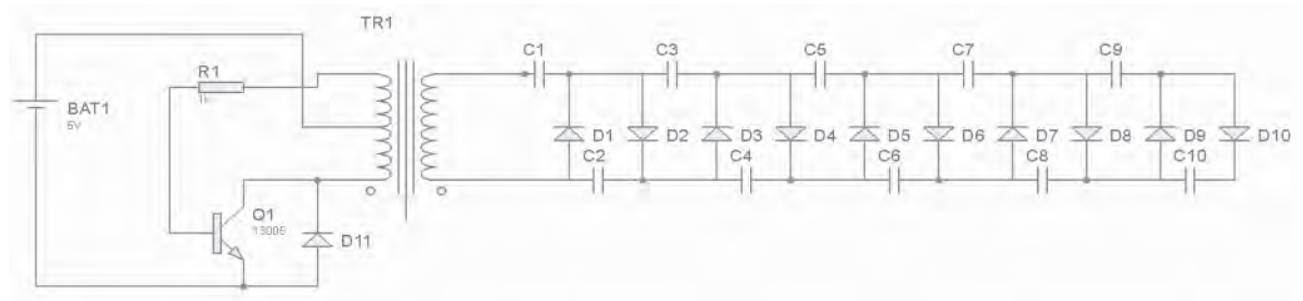

Figure 2: Circuit diagram for electric shock generation 
Now for the generation of electric shock, as shown in a circuit diagram, when a small DC voltage is applied to the center tap of the primary of transformer and through the resistor to the gate of the MOSFET, MOSFET starts to conduct. The current also flows towards the drain to the negative of the battery. The magnetic field will be generated in the primary that induces the voltage in the secondary (inductor). The secondary voltage will be much higher than the primary voltage because of the larger number of turns in the secondary. One side of the primary in a center tap also induces current in the other side of the primary which opposes the original voltage due to which 0 voltage will be in the gate which turns MOSFET off. This cycle repeats again and again at several $\mathrm{kHz}$ of frequency. It is an oscillator which oscillates current and changes the input small DC voltage to fluctuating higher AC voltage. The voltage generated depends upon the relation

$$
V_{s}=\frac{V_{p} N_{s}}{N_{p}}
$$

The equation (1) calculates the voltage generated in the secondary of transformer with the help of voltage in primary and number of turns in primary and secondary. The obtained voltage is then passed to the voltage multipler for further multiplication of voltage as shown in figure.

\section{RESULTS}

Our designed system tracks the location and reads the temperature of a person and sends the value to the authorized phone number via GSM. The authorized phone number is first needed to be saved in the SIM card. The phone number can be thus modified easily. We have experimented our device in realtime on several places. We have also verified our result depending on the obtained output. Multiplse checking of the obtained data, their real time response, error, compatibility, safety issues, everything needs to be considered for the final validation of our device. In the figure below, we can see the output to the phone number sent by SIM inserted in GSM module containing Google URL and temperature.

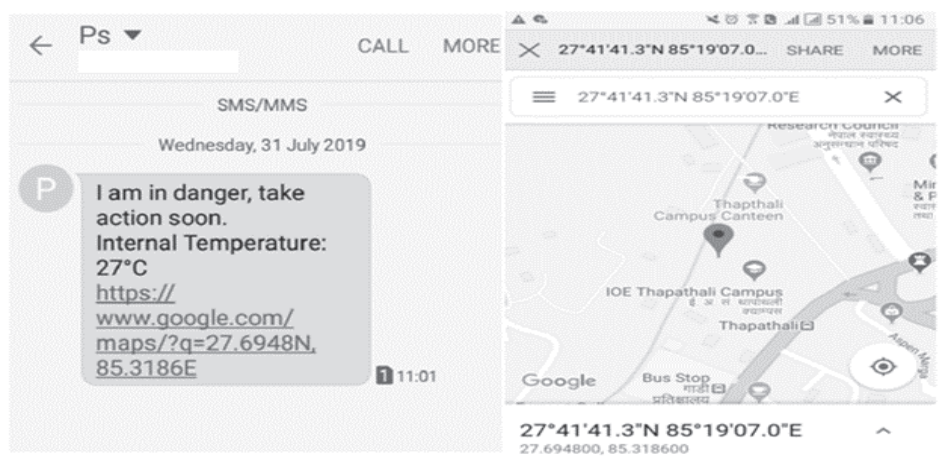

Figure 3: Output to the phone number

For the generation of electric shock, small DC voltage is first changed to approximately $260 \mathrm{~V}$ AC by oscillating the DC current. This obtained voltage is then passed to the voltage multiplier. The voltage multiplier is the combination of multiple number of capacitors which store charges one by one and discharge a very high voltage at once. This device generates a spark of about $2 \mathrm{~mm}$ so the voltage is likely approximated to be more than $1 \mathrm{KV}$.

Although our system has worked successively in real time utilization, it is still not completely error free. The output location given by GPS has some deviation from expected and exact location of that position. The temperature input from LM35 has also given slightly deviated value from exact temperature. 
Calculation of error is given by the formula:

$$
\text { Error }_{\%}=\frac{\text { Expected output }- \text { Obtained output }}{\text { Expected output }} \times 100 \%
$$

The device has been checked multiple times considering several critical situations for the final validation.

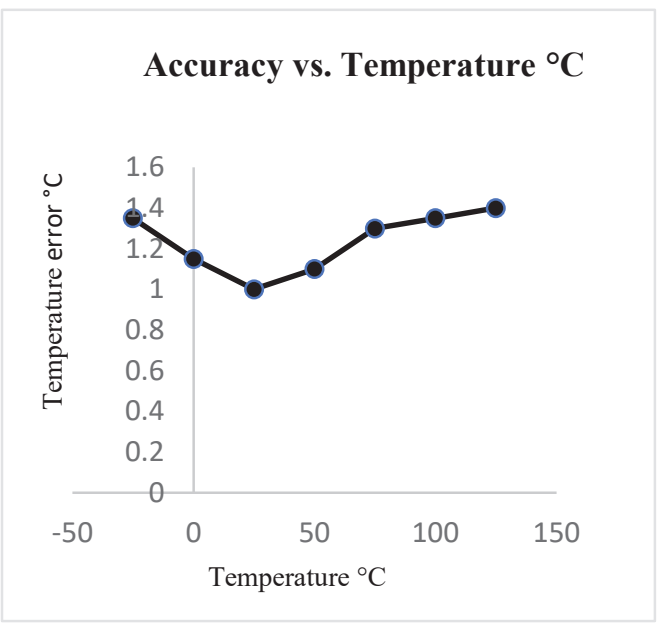

Figure 4 LM35 temperature sensor error

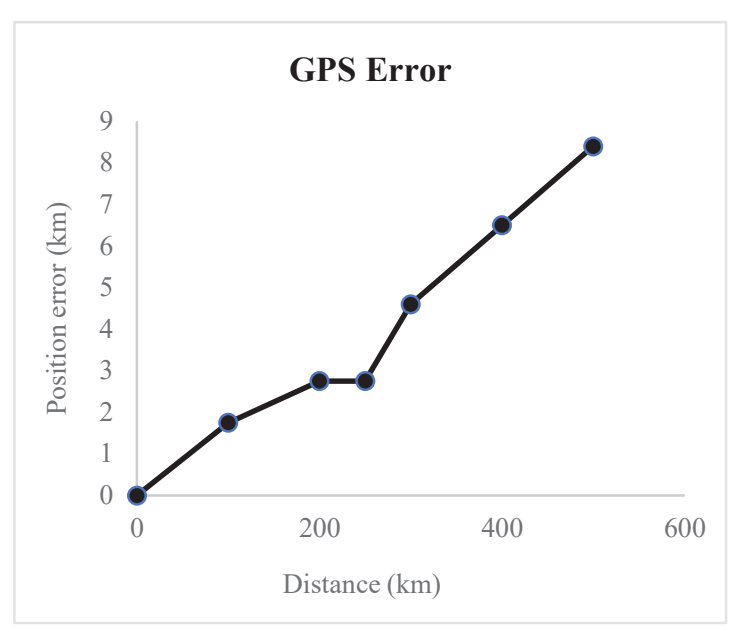

Figure 5 NEO 6m GPS module error

The above graph is based on the output given by our device. The error may be due to the sensor and module we used in our project, their accuracy, realtime time response and sensitivity, and different external and internal noises.

\section{CONCLUSION}

It is a smaller and portable system and it cannot be identified easily as a communication device that is, only the user has the knowledge about the system, third person will not be aware of it as a security system. It can be easily fit within smaller gadgets like watches, bags, shoes, under garments, etc. It can track the person even if they are in a less coverage area. So, this system can be carried anywhere easily and used at any time without much user interaction and with best functionality.

\section{ACKNOWLEDGMENT}

We are thankful to Institute Of Engineering, Thapathali campus for providing us a pleasant environment, Lab and development facilities and support. We would like to express our special gratitude towards our project supervisor Associate Professor Er. Rama Bastola ma'am for providing insights on thse electronic components, diagnosing the bug that occurred in development, and finding the solution to related problems. We would like to express our appreciation to our project coordinator Er. Dinesh Baniya Kshatri for providing necessary guidelines and support to draft this project. 


\section{REFERENCES}

[1] "N. Spotlight," News Spotlight Online, [Online]. Available: https://www.spotlightnepal.com/2018/07/30/1450-rape-cases-reported-nepal/.. [Accessed 8 July 2019].

[2] U. K. Reddy, "Self Defense System for Women Safety with Location Tracking and SMS Alerting," International Journal of Innovative technologies, vol. 05, no. 04, pp. 0590-0591, 2017.

[3] "wikipedia," [Online]. Available: https://en.wikipedia.org/wiki/AVR_microcontrollers. [Accessed 01 August 2019].

[4] micorchip, Microchip Technology, [Online]. Available: https://www.microchip.com/wwwproducts/en/ATmega32. [Accessed 27 July 2019].

[5] "Potentiallabs," Potentiallabs, [Online]. Available: https://potentiallabs.com/cart/lm35-tempsensor-india. [Accessed 02 January 2020].

[6] A. Alciato, "Wikipedia," [Online]. Available: en.wikipedia.org/wiki/Proteus.. [Accessed 05 June 2019].

[7] "software.informer," [Online]. Available: https://atmel-studio.software.informer.com/6.2/. [Accessed 01 July 2019].

[8] D. Raja, "CircuitDigest," [Online]. Available: https://circuitdigest.com/microcontrollerprojects/avr-microcontroller-lm35-temperature-sensor-based-digital-thermometer. [Accessed 09 June 2019].

[9] A. Muhammad, The AVR Microcontroller and Embedded Systems, Pearson Educations, 2011.

[10] A. Maharjan, "A Survey on Women's Security System using GSM GPS," International Journal Innovative research in Computer and Communication Engineering, vol. 5, no. 2, Feb-2017. 